tradition that the basis of anatomy was an intensive study of topographical detail at the macroscopic level. The student's attention was reoriented towards the living tissues of which the body is composed, and inspired by being brought 'to vantage points on the advancing front of scientific adventure,' to quote the preface to this $4^{\text {th }}$ edition. Partly as a result of the emphasis which had been placed on the study of macroscopic detail, the research and teaching interests of anatomists had become almost completely divorced. This book has done more than any other to bring them together, and to show students that anatomy is a living and advancing science as satisfying to an active intelligence as any other.

The 4th edition has preserved the admirable qualities of its predecessors. Some new material has been added and parts have been rewritten. A number of the most recent advances, e.g. those resulting from the use of the electron microscope, are now included, but it is pleasant to see that the changes have increased its size by no more than a few pages. It still remains the best introduction to the study of anatomy, and can also be read with both pleasure and profit by those whose anatomical studies lie mainly in the past.

\section{INTRODUCTION TO DENTAL ANATOMY}

By J. H. Scott, D.Sc., M.D., L.D.S. and N. B. B. Symons, M.Sc., B.D.S. Second edition. Pp. $\mathrm{xi}+344$, with 219 illustrations. Edinburgh: E. \& S. Livingstone, Ltd. I958. 2 gns.

Messrs. Scott and Symons have now made an Introduction to Dental Anatomy into a comprehensive survey of the subject. This has been achieved by adding a section dealing with the macroscopical study of human teeth; by re-editing, and in many instances, re-writing the text of the first edition.

The continuity of the book makes it very ' readable ' and the photographs and diagrams are of high quality, although in the first chapter on the Form and Relations of Human Teeth, the detail photography is not quite up to standard of the remainder. However, as every student should have a set of natural teeth to study in conjunction with the text, this is only a minor fault.

An excellent textbook both for students and as preparatory reading for postgraduate study, the comprehensive references being particularly useful in this respect.

J.N.

\section{THE CEREBROSPINAL FLUID}

\section{Production, Circulation and Absorption}

Edited by G. E. W. Wolstenholme, O.B.E., M.A., M.B., B.Ch., and Cecilia M. O'ConNor, B.Sc. Pp. xii +335 , illustrated. I958. 5os. London: J. \& A. Churchill Ltd.

This book is the report of a Ciba Foundation
Symposium and is concerned with the production, circulation and absorption of the cerebrospinal fluid, although this necessarily requires a considerable amount of anatomy. The chapters are by a distinguished series of contributors and it forms a most valuable summary of the recent work on the subject.

It is lavishly illustrated and because the illustrations are so frequent the entire book has been produced on glossy paper. There are, however, certain faults in editing and it is irritating to have a black and white illustration, e.g. on page 128 , which has a caption telling one that the arteries are outlined in blue and the veins in red. In spite of this minor criticism the book is strongly recommended.

K.W.C.

\section{CHEMICAL METHODS IN CLINICAL MEDICINE}

By G. A. Harrison, M.D., F.R.I.C. Fourth Edition. Pp. 667, figs. 158 . London: J. \& A. Churchill Ltd. 65 s.

Ten years have elapsed since the last edition of this standard work appeared. Dr. Harrison has added a great deal of new material but managed to compress it into few extra pages. There are welcome new accounts of photo-electric absorptio meters and of the flame photometer (it is a pity that the author still clings to milligrammes in describing sodium and potassium standards). Chro matography and electrophoresis are described: The author's prejudice against the estimation of the I 7-ketosteroids in urine seems hard to justify. Here and there certain changes of fashion might have led to changes of emphasis: few clinicians now bother with the urea concentration test for example, while PSP excretion, which is dismissed in three lines, is estimated in most American laboratories. The author's views on diabetes are unorthodox; it is surprising to find that mild diabetics should either be warned not to lose weight (p. 193) or told to maintain it (p. 194) when a large number of obese patients with glycosuria regain normal carbohydrate tolerance when weight is reduced, a fact which is not mentioned. The section on diabetic coma is valueless and would be better omitted. There is a short section on intravenous fluids; it might with advantage include some notes on potassium therapy; the author's only reference to a paper on post-operative fluid and electrolyte therapy is dated 1938 . The section on liver function tests is more topical, but most workers would like to see a description of the thymol turbidity test included, though the author appears to have no use for it.

These shortcomings do not detract from the value of the book as a whole. Comprehensive and clearly written, beautifully produced and inexpensive, it must remain a necessary standby in every routine laboratory. 